\title{
The Adverse Effect of Proprioceptive Sense in Head-Neck according to Smartphone Usage
}

\author{
Sung Min Son \\ Department of Physical Therapy, College of Health Science, Cheongju University, Cheongju, Korea
}

Purpose: Most studies have reported pain in the head-neck and upper-limbs according to smartphone usage, which is related to the proprioception sense in the head and neck, but there have been few studies. Therefore, the aim of this study was identify the adverse effects of the proprioceptive sense in the head-neck according to smartphone usage.

Methods: Twenty-seven young adults (male: 9, female: 18) were enrolled in this study. The proprioceptive sense was measured through the joint reposition sense error and neural positon error in the head-neck during smartphone usage for 0,5 , and 20 minutes. The Noraxon MyoMotion system was used to record the joint position angle and neutral positon in the head-neck. One-way repeated ANOVA was used to identify the differences between the three smartphone use durations and the least-squares difference was used as a post hoc test. The data were analyzed using SPSS 18.0 software.

Results: The joint reposition sense error and neural positon error in the head-neck were significantly different among the 0,5 , and 20 minutes of smartphone usage $(p<0.05)$. In the post hoc test, the joint reposition sense error and neural positon error showed a significant difference between smartphone use for 0 minute and 5 minute, and between smartphone use for 0 minute and 20 minutes.

Conclusion: This study suggests that smartphone use within 5 minutes can have adverse effects on the proprioceptive sense. Therefore, it is necessary to consider the appropriate use time and break time when using smart phones.

Keywords: Smartphone, Proprioceptive sense, Head-neck

\section{서 론}

지난 수십 년간 휴대용 통신장비는 빠르게 전세계적으로 보급되고 있으며, 특히 현대 사회인들은 인터넷 검색과 소셜 네트워크 서비스 (social network services) 사용을 위한 스마트폰(smartphone) 사용이 급 속히 증가하고 있다. 대한민국은 2011년 기준 전체 대한민국 국민의 $40 \%$ 이상인 2,000만 명이 휴대폰을 사용하고 있다고 보고되었다. 스 마트폰은 빠른 접근성과 다양한 앱을 통한 정보 습득과 업무수행 뿐 만 사회관계 형성 및 여가생활을 제공하는 편리한 기능을 담당한다. 하지만, 과도한 사용은 어깨, 팔꿈치, 손목 및 손가락 관절뿐만 아니 라 목과 체간의 척추 관절에서 건강과 관련한 다양한 근골격계 질환 을 유발할수 있다.1,3-5

컴퓨터 사용 및 사무직 작업자와 같이 장시간 반복적으로 책상에 서 앉은 자세로 작업을 필요로 하는 사람들은 목과 어깨 주위에 부 적절한 자세가 유발될 수 있으며, 이러한 문제는 비정상적인 신체정
렬로 이끈다. ${ }^{6-8}$ 더욱이, 스마트폰과 같은 모바일 기기(mobile device)는 데스크탑(desktops) 사용자들보다 더욱 쉽게 목과 어깨 주위에 스트 레스가 발생하고 근피로가 빨리 유발된다고 하였다.9,10 이는 스마트 폰 혹은 모바일기기는 데스크탑에 비해 장비의 화면이 작아 일반적 으로 스마트폰을 허리 혹은 무릎 위 높이에서 사용하고 있으며, 이는 목을 전방과 아래쪽을 향하는 양상으로 자세를 만들 수 있다. 이와 같이 반복적으로 노출된 비정상적인 머리와 목의 자세는 앞쪽머리 자세(forward head psoture)의 원인이 된다." 앞쪽머리자세는 목과 어 깨 주위의 근육과 인대에 스트레스와 긴장도를 높이고 쉽게 근피로 를 발생시켜 근막동통증후군(myofascial pain syndrome)과 같은 근골 격계 질환이 발생한다고 보고하였다.12,13 정상적인 머리-목 위치에 비 교했을 때, 앞쪽머리자세를 가진 대상자는 고리중쇠관절과 고리뒤 통수관절을 포함한 위쪽 머리-목뼈에서는 폄 토크가 생산되고, 특히 머리-목 무게의 중심점이 움직임 축에서 멀어지면서 정상적인 자세 에 비해 외적 모멘트 팔의 길이가 증가되어 굽힘 토크가 2 배 이상 증
Received Mar 13, 2018 Revised Apr 23, 2018

Accepted Apr 23, 2018

Corresponding author Sung Min Son

E-mailssm0417@hanmail.net
Copylight (C) 2018 The Korea Society of Physical Therapy

This is an Open Access article distribute under the terms of the Creative Commons Attribution Non-commercial License (Http:// creativecommons.org/license/by-nc/4.O.) which permits unrestricted non-commercial use, distribution, and reproduction in any medium, provided the original work is properly cited. 
가되며, 이에 따라 머리-목 폄 근에 대한 스트레스와 부하는 증가하 게 된다. ${ }^{14}$

부적절한 자세로 인해 비정상적인 근육 활성도, 인대의 변성 및 근 피로가 발생되어 고유수용성감각에 부정적인 영향을 줄 수 있다.15 고 유수용성감각은 근방추의 영향을 받으며, 근방추는 근육의 길이변화 와 속도를 감지한다. ${ }^{16}$ 장시간 스마트폰의 사용은 앞쪽머리자세를 유 발시켜 위쪽 목뼈부위의 과도함 폄과 아래쪽 목뼈부위에서는 굽힘을 유발시켜 근방추에 부정적인 영향을 줄 수 있다.1718 선행연구에서 좋 지 못한 머리-목 자세를 가진 앞쪽머리자세 대상들은 기계적수용기 (mechanoreceptor) 및 고유수용성감각과 관련된 문제를 확인하였고, 목 근육들의 근방추(muscle spindles) 민감도(sensitivity)의 변화와 함께 목관절들의 움직임에 대한 운동감각(kinesthetic)에서도 정확도가 감 소되었다고 보고하였다.19,20 대학생들은 스마트폰을 통해 문자 주고받 기, 스케줄관리, 인터넷 앱 및 검색 사용 시간은 평균적으로 하루 3.5 시간 이상 소비하고 있으며, ${ }^{21}$ 선행연구에서 영상단말기 사용기간이 길어질수록 목과 체간의 굽힘과 위쪽 목뼈의 폄은 더욱 증가된다고 보고하였다. ${ }^{22}$ 지금까지 선행연구들의 대부분은 스마트폰 사용으로 인한 머리목과 상지의 통증에 관한 연구가 대부분이었으며, 11,21 스마 트폰 사용에 따른 머리-목의 고유수용성감각에 관련한 선행연구들 은 없었다. 그래서, 본 연구의 목적은 스마트폰 사용에 따른 머리-목 관절의 고유수용성감각에 미치는 영향을 알아보고자 한다.

\section{연구 방법}

\section{1. 연구대상}

본 연구는 20 대 대학생 남녀 27 명을 대상으로 하였다. 실험에 참여하 기 전 모든 대상자들은 본 실험에 대한 설명을 충분히 듣고 목적을 이해하였으며, 실험 전에 자발적으로 참여에 동의하였다. 대상자 제 외 기준은 1) 실험에 영향을 줄 수 있는 머리와 목의 근골격계 및 신경 학적 결함이 있는 자, 2) 앞쪽머리자세 대상자, 3) 실험 결과에 영향을 줄수 있는 체계적인 운동을 하고 있는 자는 연구에서 제외하였다. 앞 쪽머리자세에 대한 평가는 대상자를 편안한 자세로 의자에 앉게 한 후 카메라를 이용하여 환자의 어깨 높이에서 대상자의 시상면(sagittal plane)을 촬영하였다. 촬영한 사진을 이용해서 머리-척추각을 확인 하기 위해 귀의 이주와 제7목뼈 가지돌기 위에 표시점을 부착하여 두 표시점을 지나는 선을 그었다. 머리-척추각은 두 표시점이 지나는 선 과 수평선상의 각도를 의미하며, 이 각도가 $54^{\circ}$ 이하일 때 앞쪽머리자 세로 평가하였다. ${ }^{10}$

\section{2. 연구절차 및 실험장비}

본 연구에서 고유수용성감각의 평가는 머리-목 굽힘 관절 재 위치감 각(joint reposition sense)과 머리-목 정 위치감각(neutral position sense) 을 통해 오차 값을 측정하였다.

\section{1) 연구절차}

관절 재 위치하기 측정은 중립 위치에 머리-목을 유지시킨 후 사전에 설정 된 특정 목표 각도(target angle)에 5 초 동안 목을 굽히게 한 후 다 시 중립 위치로 위치시켰다. 그리고 10초 후목표 각도로 머리-목 굽힘 을 재현하도록 하였다. 관절 재 위치하기 오차를 측정하기 위한 머리목 굽힘 목표 각도는 목 주변 연부조직과 구조물들의 손상을 최소화 하기 위해 대상자의 최대 목 관절가동 범위를 측정 후 관절가동범위 의 $66 \%$ 에 설정하였다. ${ }^{23}$ 이때 특정 목표 각도와 재현된 굽힘 각도와의 차이를 관절 재 위치하기 오차 값으로 정의하였다. 관절 재 위치하기 고유수용성감각 평가는 스마트 사용 전, 스마트폰 사용 후 5 분, 스마 트폰 사용 후 20 분, 각각 3 회씩 측정하였고 3 회 평균값을 측정값으로 채택하였다.

머리-목 정 위치 고유수용성감각은 스마트폰 사용 전후 대상자가 인식하는 신체중력선(line of gravity)에 대한 변화를 평가하기 위하여 실시하였다. 정 위치 자세감각이란 머리와 목의 중립 위치를 기억하 고 움직임이 시행한 후 중립 위치로 가능한 정확하게 되돌아가는 것 을 말한다. ${ }^{24}$ 측정은 최초 스마트폰 사용 전 대상자에게 똑바로 앉은 자세(upright sitting position)를 취하도록 지시하였고, 이 위치를 영점 (reference point)으로 설정하였다. 그리고 스마트폰 사용 후 5 분과 20 분에 각각 추가적으로 정 위치자세 고유수용성감각을 평가하였다. 각 시간마다 고유수용성감각 평가는 3 회씩 측정하였고, 3 회 평균값 을 측정값으로 채택하였다.

실험에 참가한 대상자들에게 스마트폰 사용 시 자세는 발목, 무릎, 엉덩관절을 $90^{\circ}$ 에 최대한 유지하고 의자에 앉아 있도록 지시하였고, 체간 및 상지는 자유롭게 움직일 수 있도록 허용하였다. 관절 위치감 각과 정 위치자세 고유수용성감각 평가 시 시각적 정보를 통한 보상 작용을 차단하기 위해 안대를 착용하였고, 충분한 연습을 통해 학습 효과를 최소화하였다. 실험에 사용된 스마트폰은 본인의 스마트폰 을 이용하도록 하였고, 자유롭게 애플리케이션 및 인터넷 등을 사용 하도록 하였다.

\section{2) 측정장비}

머리-목 굽힘 관절 재 위치하기 오차와 머리-목 정 위치 오차를 측정 하기 위해 삼차원 동작 분석 시스템인 Noraxon MyoMotion (Scottsdale, AZ, USA)을 사용하였다. MyoMotion은 3개의 센서를 이용하여 이마의 눈썹 사이, 7 번째 목뼈의 가시돌기, 양쪽 엉덩뼈위능선의 사이 에 부착하여 머리-목의 움직임 각도를 측정하였다. 머리-목의 움직임 각도는 센서와 연결된 화면에 보일 수 있게 설계되었다. 대상자들의 
머리-목 관절의 중립 위치 $0^{\circ}$ 값을 확인하기 위해서 똑바로 앉은 자세 를 취하도록 지시하였고, 이 값을 중립 위치 값 $0^{\circ}$ 로 설정하였다.

\section{3. 자료처리}

모든 데이터는 SPSS 12.0 (SPSS Inc., Chicago, IL, USA) 버전을 사용하 였다. 대상자의 일반적 특성은 Kolmogorov-Smirnov 검정을 통해 확 인하였다. 스마트폰 사용시간 0 분, 5 분, 20 분에 따른 고유수용성 감각 의 변화를 확인하기 위하여 일요인 반복측정 분산분석(one-way repetitive ANOVA)을 사용하였으며, 사후검정(post-hoc)은 least significant difference (LSD: 최소유의차 검증)를 사용하였다. 유의 수준은 $\alpha=0.05$ 로 설정하였다.

\section{결 과}

대상자들의 일반적 특성은 Table 1 과 같다. Table 2 는 스마트폰 사용 시간에 따른 머리-목의 고유수용성감각을 확인하기 위한 머리-목 관 절 굽힘 재 위치하기 오차와 정 위치 자세 오차를 나타낸다. 스마트폰 사용시간 0 분, 5 분, 20 분 따른 일요인 반복측정 분산분석에서 머리목 관절 굽힘 재 위치하기 오차와 정 위치 자세 오차 비교에서 모두 유의한 차이를 나타냈다 $(\mathrm{p}<0.05)$. 사후 검정에서 머리-목 관절 굽힘 재 위치하기 오차와 정 위치 자세 오차 모두 0 분과 5 분에서 유의한 차이가 있었고 $(\mathrm{p}<0.05), 0$ 분과 20 분 차이에서도 유의한 차이가 있었 다 $(\mathrm{p}<0.05)$. 하지만, 5 분과 20 분 사이에서는 유의한 차이가 나타나지 않았다 $(\mathrm{p}>0.05)$.

Table 1. The general characteristics of subjects

\begin{tabular}{lc}
\hline & Subject $(\mathrm{n}=27)$ \\
\hline Male/Female & $9 / 18$ \\
Age (year) & $20.67 \pm 0.78$ \\
Height $(\mathrm{cm})$ & $167.07 \pm 9.04$ \\
Weight $(\mathrm{kg})$ & $62.55 \pm 10.46$
\end{tabular}

Mean \pm S.D.

Table 2. Change of proprioception sense according to smartphone usage time in head and neck

\begin{tabular}{lcc}
\hline Smartphone usage time & $\begin{array}{c}\text { Joint Reposition error } \\
\text { (degree) }\end{array}$ & $\begin{array}{c}\text { Neutral position error } \\
\text { (degree) }\end{array}$ \\
\hline 0 minute & $2.01 \pm 1.72$ & 0 \\
5 minutes & $4.45 \pm 1.98^{\mathrm{a}}$ & $3.44 \pm 2.27^{\mathrm{a}}$ \\
20 minutes & $4.93 \pm 3.81^{\mathrm{b}}$ & $3.75 \pm 1.95^{\mathrm{b}}$ \\
p-value & $0.000^{\star}$ & $0.000^{*}$ \\
\hline
\end{tabular}

Values are presented as mean \pm standard deviation.

* significant difference according to smartphone usage time $(p<0.05)$; ${ }^{a}$ signifi-

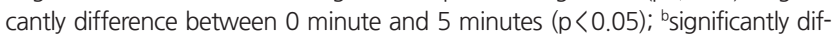
ferent between 0 minute and 20 minutes $(p<0.05)$.
고 찰

스마트폰 사용과 관련한 선행연구들 대부분은 체간의 자세변화와 통증에 대한 연구들이었다.11,21,25 그래서, 본 연구에서 스마트폰 사용 시간 0 분, 5 분, 20 분 따라 머리목 관절의 고유수용성 감각에 변화가 발생하는지 확인하였다. 연구 결과 스마트폰 사용 전과 비교해서 사 용시간 5 분 후에 머리목 굽힘 관절 재위치감각과 정 위치 자세 오차 에서 유의하게 오차각도가 증가하였고, 5 분 후와 20 분 사이에서는 유의한 차이가 없는 것으로 나타났다. 우리의 연구는 스마트폰 사용 은 머리-목 관절의 고유수용성감각에 부정적 영향을 줄 수 있고, 장 시간 반복적인 스마트폰 사용은 머리-목 영역에 근골격계 질환을 유 발시킬 수 있음을 시사한다.

본 연구의 결과에서는 스마트폰 사용 후 5 분 이내 고유수용성감 각에 부정적인 영향을 발생시킬 수 있다고 나타났다. 스마트폰 사용 은 위쪽 목뼈부위의 과도함 폄과 아래쪽 목뼈부위에서는 굽힘 움직 임이 나타나며, 여러 선행연구들에서도 스마트폰사용은 앞쪽머리자 세를 유발시킨다고 하였다.111718 앞쪽머리자세는 머리의 중심선을 앞 쪽과 위쪽으로 이동시켜 구조적으로 목에서 지탱하는 머리의 무게 를 더욱 증가시키게 되며, 이는 머리-목 주위의 근육 및 인대의 부하 와 스트레스를 증가시킨다.926 더욱이 스마트폰은 작은 화면으로 구 성되어 있고 사용자가 직접 들고 있어야 하기에 스마트폰을 무릎 혹 은 허리 부분에 위치하고 사용하고 있다. 이는 일반 데스크탑 사용자 에 비해 목을 더 전방과 아래쪽을 향하는 양상으로 자세를 만들 수 있다.Szeto and Lee ${ }^{9}$ 의 연구에서 스마트폰과 같은 작고 이동성이 있는 영상장비의 사용은 기존 데스크탑과 같은 영상장비에 비해 사용자 들의 근골격계에 더 많은 영향을 줄 수 있다고 보고하였다. Greig 등27 은 영상장비 사용은 목세움근(cervical erector spinae)과 위등세모근 의 근활성도가 정상적인 자세보다 최대 $5 \%$ 이상 더 동원된다고 보고 하였고, ${ }^{27}$ 이러한 주변 구조물의 변화는 구조적으로 근육의 피로를 더 많이 발생시킬 수 있으며, ${ }^{25}$ 고유수용성감각에도 부정적인 영향을 미칠 수 있다. 선행연구에서도 본 연구와 유사한 연구 결과가 나타났 으며, Reddy et al. ${ }^{23}$ 의 연구에서 뒤쪽 목 근육 부위에 피로도를 증가시 킨 후 관절 재 위치 감각을 평가하였을 때, 관절 재 위치하기 오차 값 이 피로를 유발시킨 후에 통계학적으로 유의하게 증가된 것으로 보 고하였다. 또한 고유수용성감각은 근방추(muscle spindle)의 영향을 받으며, 근방추는 근육의 길이와 속도에 반응하여 활성도에 변화가 발생하게 된다. ${ }^{20}$ 장시간의 스마트폰 사용은 정상적인 앉은 자세와 비 교했을 때, 위쪽 목뼈의 굽힘 근육과 아래쪽 목뼈의 폄 근육의 길이 변화를 유발시켜 근방추에 비정상적인 활성과 관절위치감각에도 부 정적인 영향을 줄 수 있다. 선행연구에서 전방머리자세를 유발시킨 후 관절 재위치 오차 값을 측정할 때 바르게 앉은 상태에서 보다 관 
절 재위치 오차 값이 더 증가하였고, 정 위치 고유수용성 감각 평가 에서도 바른 앉은 자세를 취한 대상자보다 앞쪽머리자세를 10 분 동 안 유지한 대상자에서 오차 범위가 더욱 증가하였다고 보고하였다.28

본 연구의 결과는 스마트폰 사용 후 5 분 이내 고유수용성 감각에 부정적인 영향을 발생시키고, 5 분 이후에는 더 이상의 고유수용성 감각의 변화를 악화시키지 않았다. 이는 스마트폰 사용 시 5 분의 짧 은 시간에도 목 주위의 근육과 인대에 영향을 줄 수 있음을 시사하 며, 스마트폰 사용 시 적절한 사용시간에 대한 준수 및 휴식 시간에 대한 고려가 필요할 것으로 사료된다. 하지만, 본 연구의 결과를 해석 하기에 고려해야 할 몇 가지 제한점이 있다. 우선 본 연구는 실험군과 비교할 대조군을 설정하지 못하였다. 그래서, 시간에 따른 자세의 변 화에 의해 고유수용성감각 변화에 대한 변수는 고려하지 못한 점이 다. 둘째, 대상자들의 수가 적고 젊은 성인을 대상으로 하여 다양한 연령층에 대해서 일반화하기에 어려움이 있다. 향후 연구에서는 이 러한 제한점을 보완한 연구들이 지속적으로 이루어져야 할 것이라 생각된다.

\section{참고 문헌}

1. Jonsson P, Johnson PW, Hagberg M et al. Thumb joint movement and muscular activity during mobile phone texting - a methodological study. J Electromyogr Kinesiol. 2011;21(2):363-70.

2. Park NK, Kim YC, Shon HY et al. Factors influencing smartphone use and dependency in South Korea. Comput Human Behav. 2013;29(4): 1763-70.

3. Kwon M, Lee JY, Won WY et al. Development and validation of a smartphone addiction scale (SAS). PLoS One. 2013;8(2):e56936.

4. Murdock KK, Gorman S, Robbins M. Co-rumination via cellphone moderates the association of perceived interpersonal stress and psychosocial well-being in emerging adults. J Adolesc. 2015;38:27-37.

5. Raustorp A, Pagels P, Froberg A et al. Physical activity decreased by a quarter in the 11- to 12-year-old swedish boys between 2000 and 2013 but was stable in girls: a smartphone effect? Acta Paediatr. 2015;104(8):808-14.

6. Eltayeb S, Staal JB, Kennes J et al. Prevalence of complaints of arm, neck and shoulder among computer office workers and psychometric evaluation of a risk factor questionnaire. BMC Musculoskelet Disord. 2007; 8:68.

7. Korhonen T, Ketola R, Toivonen R et al. Work related and individual predictors for incident neck pain among office employees working with video display units. Occup Environ Med. 2003;60(7):475-82.

8. Wahlstrom J, Lindegard A, Ahlborg G Jr et al. Perceived muscular tension, emotional stress, psychological demands and physical load during VDU work. Int Arch Occup Environ Health. 2003;76(8):584-90.

9. Szeto GP, Lee R. An ergonomic evaluation comparing desktop, notebook, and subnotebook computers. Arch Phys Med Rehabil. 2002;83(4):527-32.

10. Nam KS, Kwon JW. The effects of head position in different sitting postures on muscle activity with/without forward head and rounded shoul- der. J Kor Soc Phys Ther. 2014;26(3):140-6.

11. Kim YG, Kang MH, Kim JW et al. Influence of the duration of smartphone usage on flexion angles of the cervical and lumbar spine and on reposition error in the cervical spine. Phys Ther Korea. 2013;20(1):10-7.

12. Visscher CM, De Boer W, Lobbezoo F et al. Is there a relationship between head posture and craniomandibular pain? J Oral Rehabil. 2002; 29(11):1030-6.

13. Yip $\mathrm{CH}$, Chiu TT, Poon AT. The relationship between head posture and severity and disability of patients with neck pain. Man Ther. 2008;13(2): 148-54.

14. Vasavada AN, Li S, Delp SL. Influence of muscle morphometry and moment arms on the moment-generating capacity of human neck muscles. Spine. 1998;23(4):412-22.

15. Taylor JL, Butler JE, Gandevia SC. Changes in muscle afferents, motoneurons and motor drive during muscle fatigue. Eur J Appl Physiol. 2000;83(2-3):106-15.

16. Allen TJ, Proske U. Effect of muscle fatigue on the sense of limb position and movement. Exp Brain Res. 2006;170(1):30-8.

17. Brumagne S, Lysens R, Swinnen S et al. Effect of paraspinal muscle vibration on position sense of the lumbosacral spine. Spine. 1999;24(13):132831.

18. Hanten WP, Lucio RM, Russell JL et al. Assessment of total head excursion and resting head posture. Arch Phys Med Rehabil. 1991;72(11):87780 .

19. Cheng CH, Wang JL, Lin JJ et al. Position accuracy and electromyographic responses during head reposition in young adults with chronic neck pain. J Electromyogr Kinesiol. 2010;20(5):1014-20.

20. Lee MY, Lee HY, Yong MS. Characteristics of cervical position sense in subjects with forward head posture. J Phys Ther Sci. 2014;26(11):1741-3.

21. Berolo S, Wells RP, Amick BC et al. Musculoskeletal symptoms among mobile hand-held device users and their relationship to device use: a preliminary study in a Canadian university population. Appl Ergon. 2011;42(2):371-8.

22. Bababekova Y, Rosenfield M, Hue JE et al. Font size and viewing distance of handheld smart phones. Optom Vis Sci. 2011;88(7):795-7.

23. Reddy RS, Maiya AG, Rao SK. Effect of dorsal neck muscle fatigue on cervicocephalic kinaesthetic sensibility. Hong Kong Physiother J. 2012;30(2):105-9.

24. Revel M, Minguet M, Gregoy P et al. Changes in cervicocephalic kinesthesia after a proprioceptive rehabilitation program in patients with neck pain: a randomized controlled study. Arch Phys Med Rehabil. 1994;75(8):895-9.

25. Choi JH, Jung MH, Yoo KT. An analysis of the activity and muscle fatigue of the muscles around the neck under the three most frequent postures while using a smartphone. J Phys Ther Sci. 2016;28(5):1660-4.

26. Straker LM, Coleman J, Skoss R et al. A comparison of posture and muscle activity during tablet computer, desktop computer and paper use by young children. Ergonomics. 2008;51(4):540-55.

27. Greig AM SL, Briggs AM. Cervical erector spinae and upper trapezius muscle activity in children using different information technologies. Physiotherapy. 2005;40(4):265-72.

28. Jeong DW, Kim YW. Changes in cervicocephalic joint position sense in sustained forward head posture. Journal of The Korean Society of Integrative Medicine. 2017;5(2):11-7. 